\title{
Giuli Shabashvili
}

Ivane Javakhishvili Tbilisi State University, Georgia

\section{Teaching strategies of second language writing component according to Georgian language data}

\begin{abstract}
Teaching/learning of writing component is one of the challenging issues in the process of second language acquisition. It is well known that, when you are teaching/learning writing component cognitive and meta cognitive processes are stimulated which means developing of linguistic competences as well as sociocultural, discourse and communicative competences of a learner. Therefore, teaching writing component is diverse action that requires consideration of various factors from teacher including planning lessons effectively, use of relevant strategies etc. The aim of the article is to demonstrate the main point of teaching writing component, discuss various activities and present their function and results.
\end{abstract}

Keywords: teaching second language; writing strategies; planning lessons.

\section{Define the issue}

Teaching/learning of writing component is one of the challenging issues in the process of second language acquisition. It is well known that, when you are teaching/learning writing component cognitive and met cognitive processes are stimulated which means developing of linguistic competences as well as sociocultural, discourse and communicative competences of learner. Therefore, teaching writing component is diverse action that requires consideration of various factors from teacher including planning lessons effectively, use of relevant strategies etc. The aim of the article is to demonstrate the main point of teaching writing component, discuss 
various activities and present their function and results.

For a long time it was considered that based on the structural approaches deliberate attempt to rise grammar competense was the final goal of teaching writing component of second language. However, in modern scientific literature grammar is considered to be supportive tool in the process of developing writing technic. Despite the fact that second language learners intensivly used structural approaches, this theory had its gaps. The researchers think that one of the weaknesses of structural approaches is that formal patterns often demonstrated brief wtritten fragments, which were based on more prepared materials than the analysis of given text. Consequently, this impeded the development of writing skills of students as they only used to compose several sentences, that on the other hand impeded learners to create other type of writing article effectively. It is clear that only the complex of syntax and grammar rules and their knowledge is neither an effective strategy of developing writing skills nor assessment tool of good writings. In eighties there was different approach of teaching writing component that meant to be writing as a whole process that is why it is called process oriented approach. According to that approach, composing written text is more recurring activity when planning, formulating ideas and editing are happening in directly writing process (P.K. Matsuda 2003). As a result of observation it is clear that new authors as a posed to the experienced authors are planning less and instead of editing they correct grammar and syntax mistakes. Taking into account this serious gap, process oriented approach includes pre-writing activities namely, group work, brainstorming strategy, preparing drafts, group editing of writing, consideration of teacher's comments (Storch, 2013, 22).

Discussing about the issue, it is important to underline the sociocultural theory of teaching second language, which gives a socio cognitive vision on language acquisition. According to that the process of learning language has cognitive and social dimensions.

A person is a social human being and her/his whole cognitive development is involved in social integration. Therefore, according to above mentioned theory for the 
process of learning verbal interaction is vital.

(Storch, 2013, 13). Sociocultural factors directly effect on formation of interaction between two persons (Ling $\mathrm{Xu}, 2009,55)$. The behavior of a person is complex process and each of her/his activity is conditioned by sociocultural background (Lantolp, J. P 2004, 83). Sociocultural theory supports using proper methods to solve problem. According to that theory, the development of person's writing language depends on proper social, historical and cultural conditions. According to sociocultural theory social interaction stimulates cognitive skills of learner. Speaking language is mediator, which transforms young learner's social world of interpersonal communication into interpersonal world of thoughts and develops higher cognitive processes. This complicated cognitive process ends up with inner speech (sometimes called verbal thoughts), that learner uses as a self regulation and guided tool when faces the cognitive problem that needs to solve.

Writing is one of these difficult cognitive operations and inner speech is the instrument of its development. The followers of this theory use term writing speech to describe learner's first attempt in writing (Viberg 2005, 100). Viberg graphicly portrays the sociocultural vision on connection of writing and verbal communication
Interpersonal

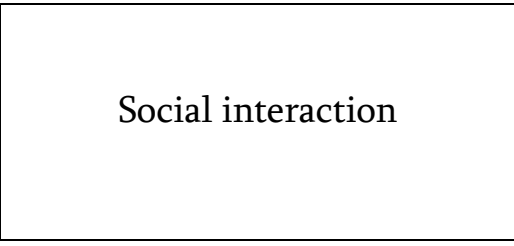

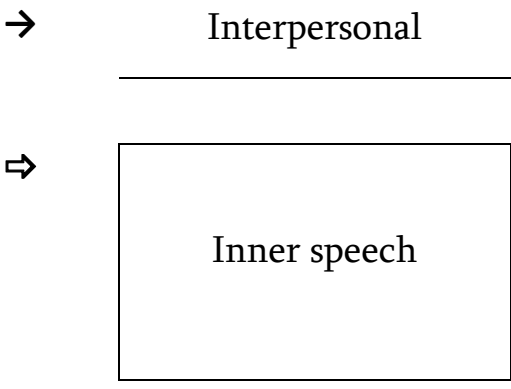

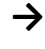

Cognition

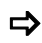

$\Rightarrow$

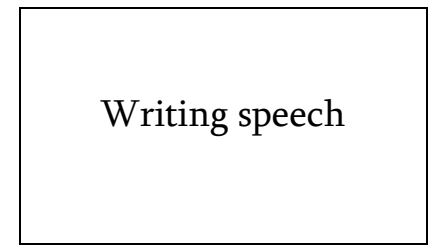

So when we are talking about the process oriented instruction of writing, social ineration as one of the determinant factors of learning only holds a little place in this process and is only engaged in pair work during editing. Therefore, considering the meaning of social ineraction new approach of teaching writing has been elaborated. This is so called collaborative writing which is based on and shares the approach of sociocultural theory. Collaborative writing means the engagement of two or more 
authors in whole writing process starting with preparatory phase and ending up with development of final product. Therefore, collaborative writing is a common process when the responsibility of composing texts is shared equally between the participants. During collaborative writing it is important to reach the agreement on what is the idea and how it should be illustrated. Collaborative work requires an inevitability of engagement in collaborative dialogue.

When the problem occurs the learners do not only rely on their linguistic recourses to solve the problem, but they use others knowledge as well. Together they can unite their linguistic recourses, joint presentation and create new knowledge. During their collaborative work they present different points of view. In case of disagreement learners offer the justifications on their ideas (Storch, 2013, 17). This can be called cognitive conflict in collective decisionmaking process. The researchers confirm that in positive environment where authors are comfortable during challenging each other, that kind of conflict might have positive effect. The conflict like that can cause generating and sharing ideas, detection of strengths and weaknesses of alternative ideas, expressing and proving clearly your own ideas. (p. 24). On the other hand it requires from students to represent knowledge more clearly and consistently.

Having regarded to collaborative writing principles C. Mulligan and R. Garofalo did some experiment where four groups of students took part. As a result of the examination researchers made the following conclusions:

1. Collaborative writing supports developing students' social skills.

2. Reduces stress and is time consuming.

3. Raises students' motivation.

4. Writing process becomes content oriented.

5. Develops grammar and structural competences of students. (C. Mulligan, R. Garofalo 2011, 8).

Below there are schematically given differences between process oriented and collaborative writing. It is clear that collaborative writing process fully includes interaction as a posed to the process oriented writing when authors use interaction only for editing and checking the text. 
Table 1

\section{Process oriented writing}

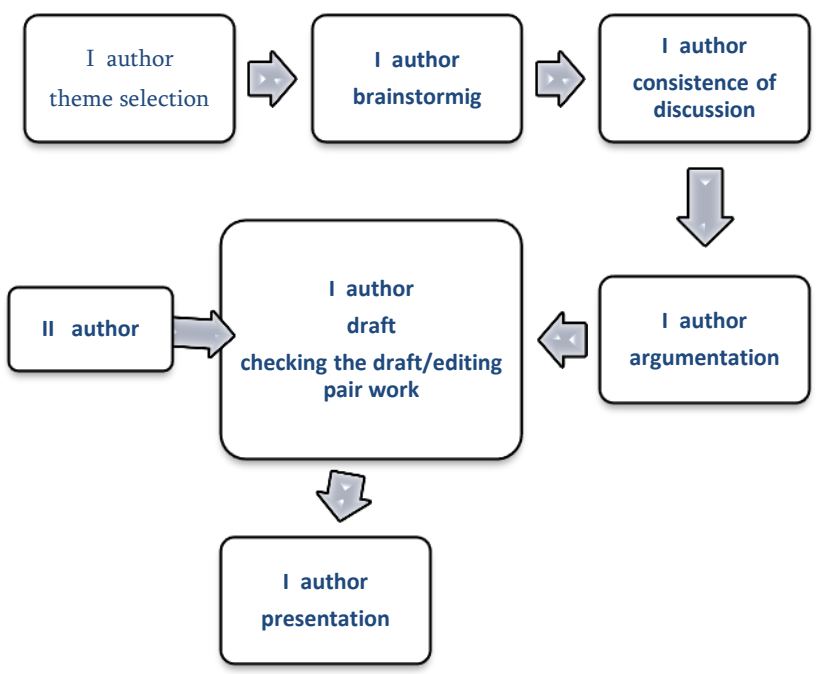

As a result of the processing and comparing different theories of teaching second language we can say that learners should be involved in interaction. The tasks that are used during this kind of interaction should be well-understood. These tasks should motivate the learner to pay attention to the form.

We could say that collaborative writing is based on three above mentioned principles (Storch, 2013, 25). Besides, in the process of writing interaction, discussion, ideas sharing become the platform for rising language

\section{Collaborative writing}

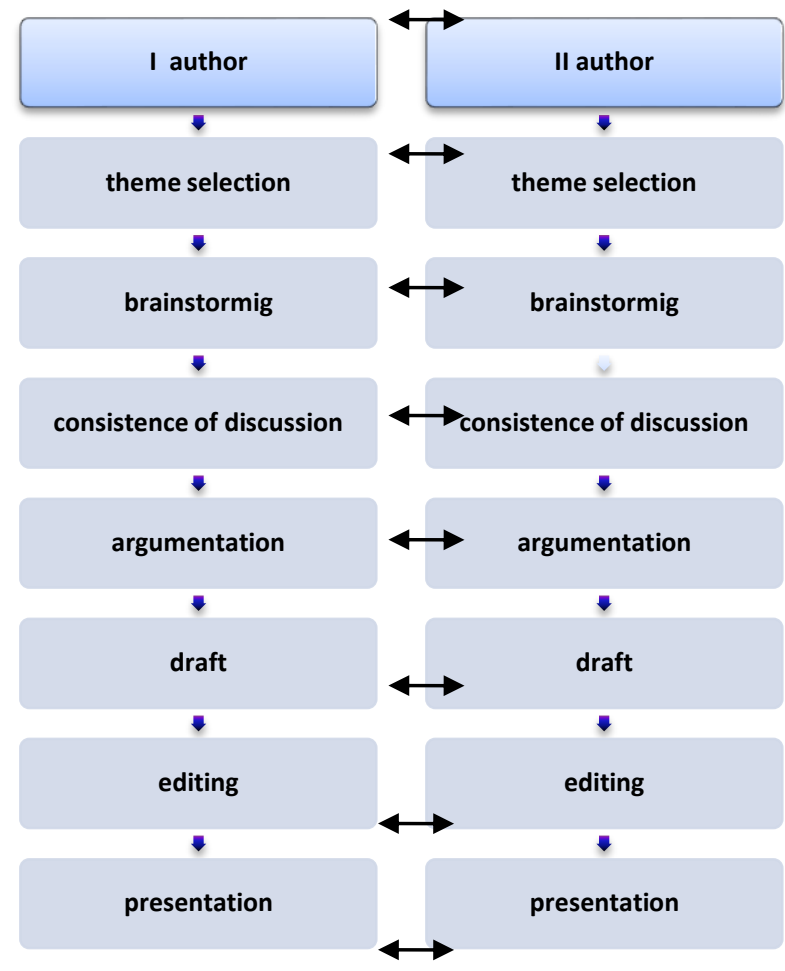

competence. That is why some researchers consider that those kind of writing activities supports learner more to deepen the language knowledge. Therefore, writing activities are more important than speaking in the process of learning second language.

\section{The types of writing activities}

In this section we will talk about the writing tasks, the types of writing activities and their functions. Generally, researchers in this field point out several types of writing activities: 
- informative writing (design brochure);

- analytical writing (answer the questions in the text);

- keep in mind-oriented writing (making notes);

- argumentative writing (design advertising poster);

- affective writing (create diaries);

- phatic writing, writing with the purpose of establish contact (create congratulation card);

- creative writing (compose a poem);

As we see, considering the aim, writing activity can have different purposes and their distribution depends on the learner's aim, level of the language knowledge and writing skills.
Beside of the various types of writing we should also talk about the writing tasks and their purpose and function in learning process.

K. Hyland provides us with detailed information about this. He points out several important aspects of the writing process that determine composing effective text. Particularly he underlines content (theme related ideas), system (linguistic forms relevant to compose text), process (making draft and editing), genre (communicative aim and rhetorical structure) and context (reader's expectation and hope).

On the other hand, researcher sorts out writing activities and shows which one relates to which factor and covers it. (K. Hyland, 2003, 114).

Table 2

\begin{tabular}{|l|c|c|c|c|c|}
\hline \multicolumn{1}{|c|}{ Text type } & Content & System & Process & Genre & Context \\
\hline Get information from written text & $\checkmark$ & & & & \\
\hline Gather foreign words for writing & $\checkmark$ & & $\checkmark$ & & \\
\hline $\begin{array}{l}\text { Brainstorming/quick writing for } \\
\text { generating ideas }\end{array}$ & $\checkmark$ & & $\checkmark$ & & \\
\hline $\begin{array}{l}\text { Mental mapping activity for preparatory } \\
\text { phase of writing }\end{array}$ & $\checkmark$ & & $\checkmark$ & & \\
\hline $\begin{array}{l}\text { Compose sentences according to the given } \\
\text { materials }\end{array}$ & & $\checkmark$ & $\checkmark$ & & \\
\hline
\end{tabular}




\begin{tabular}{|c|c|c|c|c|c|}
\hline Understanding the purpose and the text & & & & $\checkmark$ & $\checkmark$ \\
\hline $\begin{array}{l}\text { Compose simple and complicated } \\
\text { sentences }\end{array}$ & & $\checkmark$ & & & \\
\hline Putting in order mixed texts and sentences & & $\checkmark$ & & & \\
\hline $\begin{array}{l}\text { Fill the gaps in paragraph with targeted } \\
\text { structures and lexical units. }\end{array}$ & & $\checkmark$ & & & \\
\hline Finish the unfinished text & & $\checkmark$ & & $\checkmark$ & \\
\hline $\begin{array}{l}\text { Authentic text analysis according to the } \\
\text { parts and the features }\end{array}$ & & & & $\checkmark$ & \\
\hline $\begin{array}{l}\text { Practical use of met language for } \\
\text { understanding the parts of the text (main } \\
\text { sentence, thesis, introduction, transitional } \\
\text { paragraph) }\end{array}$ & & & & $\checkmark$ & \\
\hline $\begin{array}{l}\text { Understanding the type of the text and } \\
\text { presentation }\end{array}$ & & & & $\checkmark$ & \\
\hline $\begin{array}{l}\text { Compare texts that are made with } \\
\text { different purposes, for different audiences } \\
\text { and according to different structures }\end{array}$ & & & & $\checkmark$ & $\checkmark$ \\
\hline $\begin{array}{l}\text { Compose other texts according to given } \\
\text { model }\end{array}$ & & $\checkmark$ & & $\checkmark$ & \\
\hline $\begin{array}{l}\text { Compose text based on the visual } \\
\text { information }\end{array}$ & & $\checkmark$ & & $\checkmark$ & $\checkmark$ \\
\hline $\begin{array}{l}\text { Making draft version based on the results } \\
\text { of preparatory phase of the writing }\end{array}$ & $\checkmark$ & & $\checkmark$ & & \\
\hline Take part in dialogue & $\checkmark$ & & $\checkmark$ & & $\checkmark$ \\
\hline $\begin{array}{l}\text { Working on academic writing principles - } \\
\text { narrative, description, argument, } \\
\text { process... }\end{array}$ & & & $\checkmark$ & $\checkmark$ & \\
\hline
\end{tabular}

The aim of the following article is to grouping the writing activities from simple to complex in order to illustrate which type of task would be more acceptable to use at different levels of language competences elementary or advance level. Therefore, we 
have the following order of writing activities:

- To collect foreign words to do writing activity;

- To compose simple and complex sentences;

- To finish unfinished text;

- Putting in order random text or sentences;

- To compose sentences according to the given materials;

- To fill in the gaps in paragraph with target structures and lexical units;

- To create mind map for the preparatory phase of writing;

- To create parallel texts according to the given pattern;

- To create drafts according to the results of the preparatory phase of writing;

- To compose text according to the visual information;

- Brainstorming/ quick writing for generating the writing ideas;

- To get information from the written text;

- To comprehend the purpose of the text;
- To comprehend and present the type of the text;

- To analyse the authentic text acccording to its features and parts;

- The practical usage of metalanguage for the comprehension of the parts of the text (main sentence, thesis, introduction, a transition between pa ragraphs);

- To compare texts composed according to different purposes, different audiences and to different structures;

- Working on the basic principles of academic writing - narrative, description, argument, process...

- To take part in the dialogue;

In the process of the teaching writing it is important to mindfully use activities and tasks with the consideration of which activity can learner handle independently and what activities require teacher's instructors and facilitation. The following scheme gives us a possibility to overview the writing strategies that are used at the first stage and that are going to be used at a higher level, for instance, in the process of composing and during independent writing (Shabashvili, 2012, 47). 
Table 3

\begin{tabular}{|c|c|c|}
\hline Writing with help & Graphology & $\begin{array}{l}\text { Writing basics (developing motor skills, orthography, } \\
\text { punctuation) }\end{array}$ \\
\hline 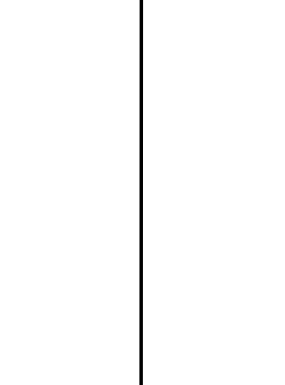 & \begin{tabular}{|l} 
Supportive \\
phase of writing
\end{tabular} & $\begin{array}{l}\text { Sample writing activities (comparision, fill in the gaps, } \\
\text { identyfing features) } \\
\text { Pattern analysis and manipulation (putting in order, } \\
\text { rearange, combine) } \\
\text { Model based writing (finish text and parallel writing) } \\
\text { Instructions for composing story (data tranfer, } \\
\text { information transfer) }\end{array}$ \\
\hline $\begin{array}{c}\mid \\
\text { Independent } \\
\text { writing }\end{array}$ & Compose & $\begin{array}{l}\text { Writing components (plan, preparatory phase of } \\
\text { writing, making draft, editing technics) } \\
\text { Writing process (compose text for target audience } \\
\text { on real or imaginary themes) }\end{array}$ \\
\hline
\end{tabular}

As we see here, at the supportive stage of the writing it is recommended to work on the pre-prepared text, doing tasks and based on the refined text composing sample story, whereas considering academic writing principles happens at higher level of learning language.

Based on the theoretical researches and practical experience we could elaborate writing activities that can be integrated on different stages of teaching language. During the one lesson/lecture different types of tasks can be used. A teacher can combine them according to which competence it intends to raise and activate. For instance, selection of a right form focuses on deepen the grammar competence. At the lower level of language competence beside of these kinds of tasks we can also offer learner to compose sentences, read sample texts, comprehend and answer the questions, and then independently compose a dialogue. In addition, we could teach a learner to express her/his own ideas/opinions clearly. Here are the concrete types and sub-types of writing tasks:

\section{The types of writing tasks:}

1. Diction:

- phonetic dictation;

- dictogloss, text dictation;

2. Selection of right forms:

- Select right grammar form;

- Select right lexical units;

- Select right phraseology;

3. Insert: 
- insert with right form (case, pronoun, numeral, tense);

- insert linguistic instruments;

- insert phraseologies;

4. Completion:

- complete sentence ;

- complete paragraph;

- complete dialogue;

- complete text;

5. Description:

- picture description;

- item description;

- family member/friend description;

- famous person description;

6. Fill in:

- fill in the gaps in sentence;

- fill in the gaps in text;

7. Conjunction:

- conjunction of synonymous and antonymous peers;

- conjunct phraseologies;

- conjunct parts of the dialogue;

8. Take out extra forms:

- take out extra lexical units/phrases;

- take out extra and incorrect grammar forms;

9. Turn into:

- turn into a pronoun, numeral, tense;

10. Underline:
- underline incorrect and extra forms;

11. Extract:

- Extract relevant lexical units, idiomatic expressions from text;

- Extract main sentences/arguments from text;

- According to specific purpose find and extract relevant information in/from text;

12. Interpret/explain:

- write explanation on pre-planned and implemented action by learner/group of learners;

13. Argumentation:

- reinforce the author's position with different arguments;

14. Express opinion:

- express your own opinion on different cases;

- Write:

- write relevant forms, explanations;

- Putting in right order:

- putting the parts of the dialogue in right order;

- putting the parts of the text in right order;

15. Compose:

- compose sentences according to the given forms; 
- compose analytical text according to the given picture;

- compose a story according to the given picture;

- compose a dialogue according to the given picture;

- Evaluate a musical performance and express your own view.

16. Answer the questions:

- write an answer of the question asked by your co-learner;

- answer the text related questions;

17. Write a brief summary of the text/dialogue;

18. Making of:

- make up sample sentences;

- make up complex sentences;

- make up dialogue;

- make up paragraph;

- make up text;

- make up official text, text ads, reports, advertisement, personal e- letter;

○ make up a fiction text;

○ make up a poem;

$\circ$ make up a text for the theme related song;

19. Preparatory phase of the writing:

- getting materials;
- brainstorming;

○ brainstorming on specific theme;

$\bigcirc$ analyse the ideas as a result of the brainstrorming;

- Make a plan;

The writing tasks are more or less presented in every textbook of second language. However, according to the circumstances and the purpose a teacher can make adjustments - simplify the tasks of make them complicated. A teacher can add various exercises and keep learner motivated. As for the selection of learning strategies and approaches, as we already mentioned collaborative writing is one of the effective forms. So a teacher can use any of these activities to make language learners do them collaboratively. Working individually is effective for doing grammar exercises. But revision of the exercises that are done in peers is an additional component for raising language competence. And this is one of the strategies of process oriented writing. Therefore, the both discussed approach of language instruction - process oriented learning and collaborative writing can be actively used in learning process. What is important is to mindfully select activities in advance, which are focused on learning goals and competences. This requires teacher's responsibility and experience. 


\section{Templates of exercises:}

In third section there are given the templates of exercises from above mentioned list. The templates are based on both process oriented and collaborative writing principles. Every template has its description, strategy list and information about upcoming results.

\section{Exercise type: \\ Comparison.}

\section{Description of exercise:}

This exercise can be done at supportive phase of writing. The aim of the exercise is to activate strategic competences, advance the levels of sentences and paragraphs. The exercise can be done at low and mid level of language acquisition. One of the effective ways to do the exercise is to use graphics and images.

\section{Strategies:}

Usually this type of activity has effective results, because learners share ideas and experience and learn foreign language from one another. The final phase is an individual work. Students should discuss loudly and compose comparative text, which then teacher will revise and assess. As we see this is a complex task and in its implementation process several cognitive strategies are involved: comprehension, obtaining information from memory, translation, explanation/verification.

\section{Example:}

We could use multimedia and graphics during carrying out this task. It is possible to allow students to listen the same melody by different artists. With the aim of raising socio-cultural competence it is desirable to present the audience Georgian melody in different musical genres (for instance, folk song and its modern interpretation). After that by considering linguistic competence we should offer learners proper lexical units for enriching vocabulary. It is better to put vocabulary comprehensively according to the parts of speech.

Verbs: sings, performing, sounds, like, listen, differ, looks like etc.

Adjectives: sad, funny, romantic, folky, loud, melodic, harmonic, easy etc.

Nouns: polyphony, song, melody, rhythm, genre etc.

Language clichés: It is important to offer learners (even at low level of learning) necessary language formuls for construction of comparison and contradiction: more, until/till, compare to this..., different from... In case of misunderstanding lexical material, it is possible to activate learners' native language and use translation (vocabulary). After developing vocabulary and phraseology a verbal discussion should be conducted by using acquired language clichés and words. It is also possible to work in peers (Shabashvili, 2012, 51-54). 


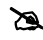

\section{Exercise type:}

Theme - in supermarket.

\section{Description of exercise:}

Theme development covers several stages and therefore several lessons/lectures could be needed. Language, discursive and sociocultural competences are activated. Activities cover the level of sentences and text.

\section{Strategies:}

When doing different exercises it is possible to use different strategies, individual work, group work, brainstorming, planning, composing text with collaborative writing principles, group presentation, make a mind maps, repeat, group editing, correct mistakes.

\section{Example:}

\section{First phase - activate knowledge}

With the principle of brainstorming and with the help of teacher learners should make a list of familiar words related to supermarket. By doing that learners activate knowledge and acquire new material based on others' knowledge.

Figure 1

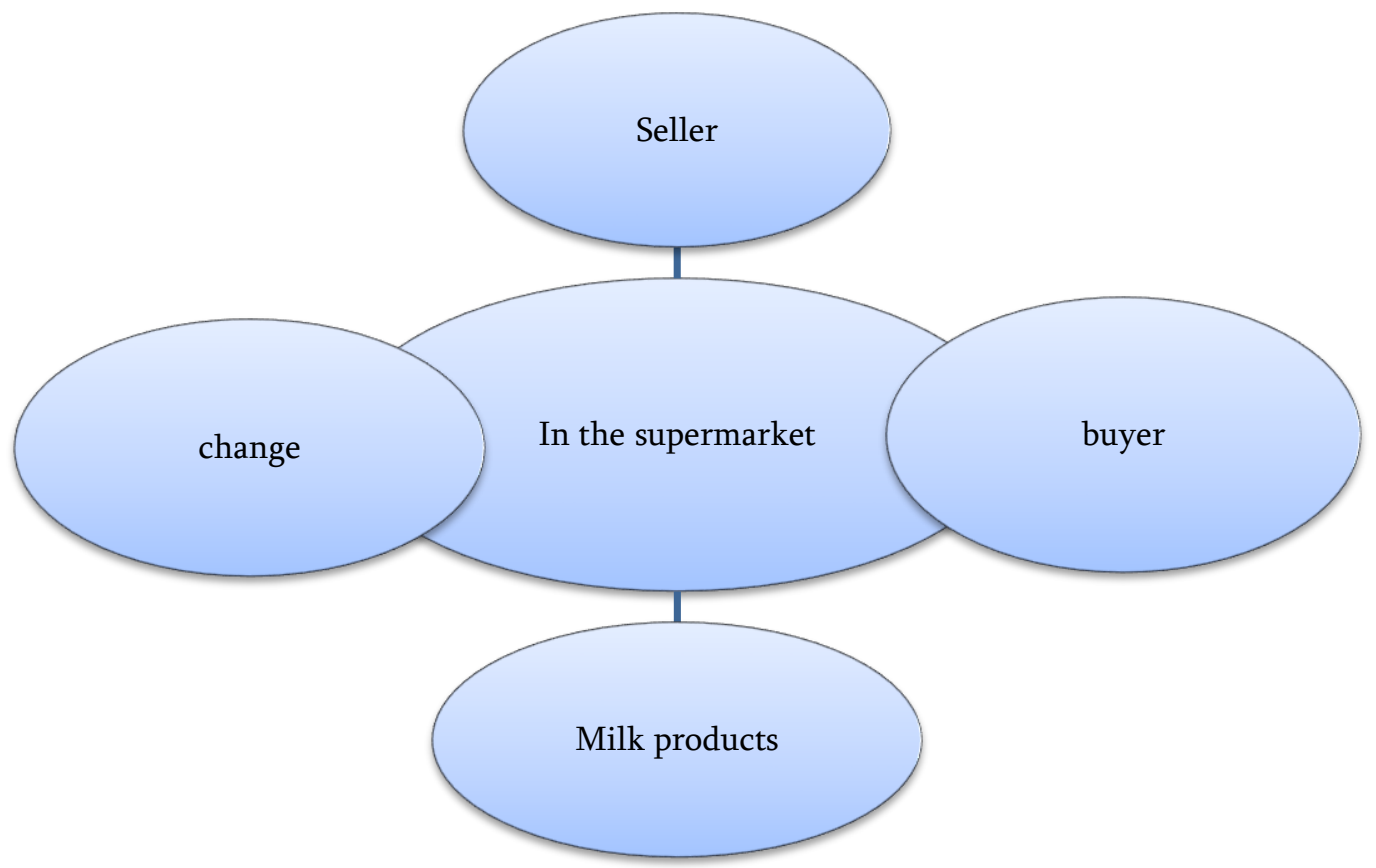

\section{Second phase - enrich lexical material}

According to the level of language command a teacher gets acquainted students with new lexical units, nouns, adjectives, adverbs and verbs. It is desirable to use various parts of speech obtained from one base by derivation and focus on their determiners. For instance: mұsbo - bsmұsbm; 


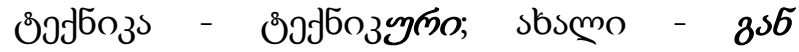

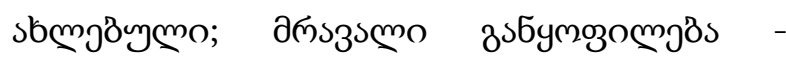

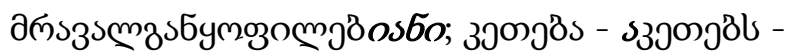

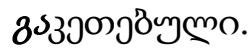

Third phase - Formulate phraseologies and question forms: what does it cost?

Fourth phase - level of sentence: make sentences with lexical units.

Fifth phase - describe a theme related picture. Group work, participate in dialogue, collaborative writing.

Sixth phase - Read theme related text. Comprehension, answer the questions in written form.

Seventh phase - Make text related questions. Collaborative writing, make and exchange questions and answer in written form.

Eighth phase - Fill in the gaps in familiar text.

Ninth phase - Do grammar exercises.

Tenth phase - Make dialogue in written form and make presentation. Collaborative writing, role games, use of familiar lexical units and phrases.

Eleventh phase - Compose descriptive text. Compose simple theme related text independently. For instance, learners can describe market near their house.
Twelfth phase - Create analytical text.

Create analytical text on following theme: How would be a good supermarket and why you think so? Learners should name 2-3 arguments on each idea. During writing they should use the following phrases: I think that... In my opinion... mostly... it is important to... etc.

Thirteenth phase - Presentation, group work. As an independent work learners should prepare presentation on following topic: supermarket. They can use audio, video and other visual materials, media instruments and the elements of role games.

\section{Exercise type:}

Theme - weather

\section{Description of exercise:}

For topic development sample text and dialogue are used. It is possible to do the exercise at mid level of language competence. Working on the topic a learner raises grammar, discursive and sociocultural competences. A learner will be able to write formal and informal texts on any issues regarding weather and also will be able to establish communication with others. There are several different types of exercises: grammar exercises, text-based activities, create independent text according to collaborative and process oriented writing principles. 


\section{Strategies:}

Beside of independent work it is also possible to involve group work, brainstorming, pair work, editing, correction of mistakes, questionnaires in order to do the following exercises:

\section{Example:}

\section{Grammar exercises:}

\section{Underline correct form}

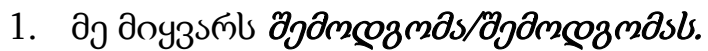

2. $\quad$ бo6m/6o6ml sj3l msas\%o jmmas.

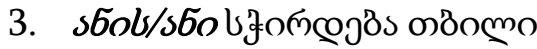
sisblşзалmо.

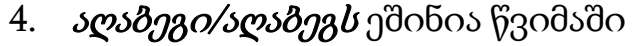
uosরiymo.

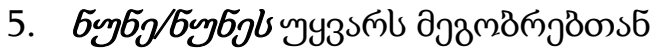
j jonsce bjoñ

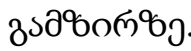

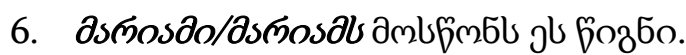

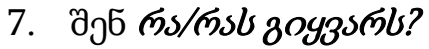

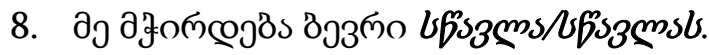

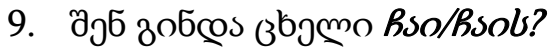

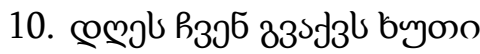
modoos/crodoost.

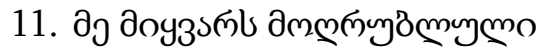
saobcoo/saobcol.

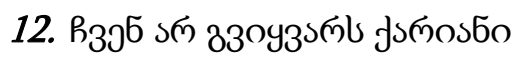
saobcoo/saobcol.

\section{Fill in the gaps:}

Hello, my is Nino. -from

Akhaltsikhe, but now in Tbilisi, I am -here at Ivane Javakhishvili Tbilisi State University and my faculty very much. I lots of new friends and everyday lectures. Living here is very

but I to go to my village. It is autumn and today in Tbilisi is

a --------------------------- weather. Outside is very and it is 13

degrees Celsius. Wind is and it is cloudy. It is raining but I rain. In rain I like with my

friends. I have an umbrella and do not afraid of in rainy weather. I autumn very much. October is my month.

3. Put the relevant forms: (he/she) has, (we) love, (they) want, (they) like, (I) love, (I) want, (I) like, (we) have, (I) have, (you) want, (it) is, (they) love, (it) has

1. Ambartsum new telephone.

2. I walking in the rain.

3. Do to go to the cinema?

4. My friends and I playing computer games. 
5. Central museum opposite to my school.

6. My school -a big sport room.

7. Rusana and Aghavni ice-cream.

8. Children -animated film about Shrek.

9. I -our new house.

10. Aghabeg and Garlen Georgian language lectures.

\section{Underline correct form:}

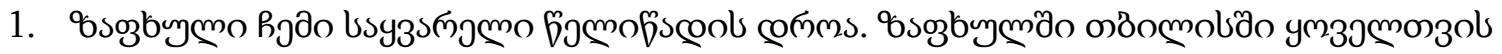
dsmost objuss/cbjesos.

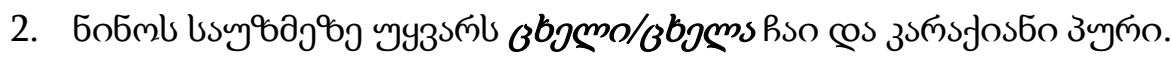

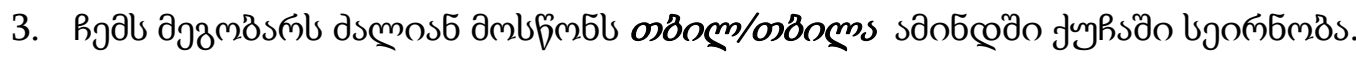

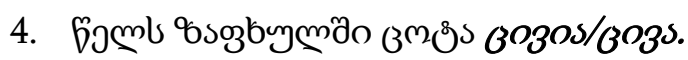

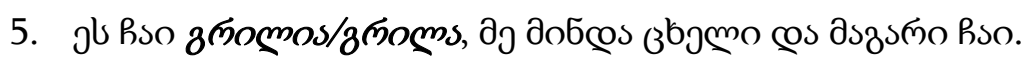

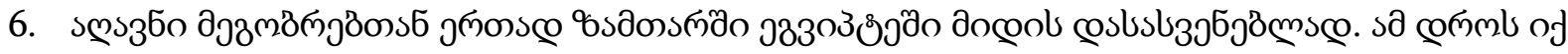

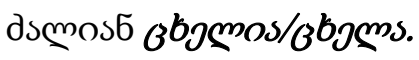

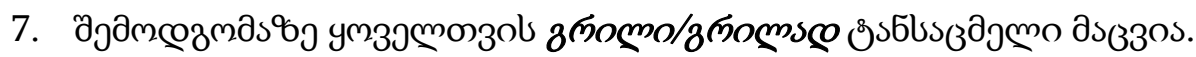

\section{Working on the text}

\section{Read text:}

Hello, my name is Nino. I am from Akhaltsikhe, but now I live in Tbilisi. I am studying here at Ivane Javakhishvili Tbilisi State University and I like my faculty very much. I have lots of new friends and I have lectures everyday. Living here is very interesting, but I want to go to my village very much. It is autumn and today it is bad weaher in Tbilisi. It is very cold outside, the temperature is 13 degrees Celsius. Wind is blowing and it is cloudy. It is raining, but I like rain. I love walking in the rain with my friends. I have an umbrella and do not afraid of walking in rainy weather. I love autumn very much. October is my favourite month.

\section{Vocabulary:}

- Rain - rainy

- Cloud - cloudy

- I love - favourite

- Sun - sunny

- Cold water - it is cold at home

- Hot coffee - it is hot outside
- Cool summer - it is cool outside.

- Warm clothes - it is warm at home

- Verbs: I have, my name is, I like, I love, I need.

- Expressions: In my opinion, I think, maybe, supposedly, in my view... 
Answer the questions:

- Who is Nino?

- Where does Nino study?

- Does Nino go to the University everyday?

- What is the weather outside according to text?

- What does Nino like?
- Which month is Nino's favourite?

- Where does Nino want to go and why?

- What kind of weather do you love and why?

- What is the weather outside? Look out of the window and describe.

\section{Working on the dialogue:}

\section{Read dialogue:}

- Hello, how are you?

- I am fine, how are you? How are you doing? Where are you going?

- Now I am going to the university, today I have many lectures. Are not you attending lectures?

- Yes, I am but I am a little bit of upset, because today is very bad weather.

- Yes, it is true. It is cloudy today and raining. It is cold outside, according to weather forecast now it's 15 degrees Celsius. It is going to be pouring rain and strong wind in the evening. I do not like rainy days.

- Really? I love rain and walking in the rain with my favourite umbrella. I remember last year I was in village, it was pouring rain outside and then a rainbow came out. It was beautiful. I love green grass and rain drops. My friends and I were happy. My dog Jackie was happy too. I miss my village so much and want to go home.

- I also miss my family. My little brother is already 5 years old. He likes playing in the rain. We have a red old umbrella at home. My brother loves it very much and often plays in the yard. He is waiting for me everyday.

\section{Answer the questions:}

- Who are the main characters of the dialogue?

- Where did they meet?

- What is the weather outside?

- What was the weather last year in the village?
- What is name of the dog?

- How old is the brother of the character in a dialogue?

- What kind of weather do the characters love? 


\section{Fill in the gaps in dialogue:}

- Hello, how are you?

- Fine, how are you? How are you doing? Where are you going?

- Now I am ----------------------to the university, Today I -many lectures, Are you attending the lectures?

- Yes, I am but I am a little bit of upset, because today is very bad weather.

- Yes, it is cloudy today and raining. It is ----------outside. According to weather forecast it is 15 degrees Celsius. In the evening it is going to be ------------rain and -----------wind. I do not like rainy days.

- Really? I love rain and -------- in the rain with my favourite umbrella. I remember last year I was in village, it was pouring rain outside and then a rainbow came out. It was beautiful. I love green grass and rain drops. My friends and I were very-------------. My dog Jackie was happy too. I miss my village so much and want to go home.

- I also ------------ my family. My little brother is already 5 years old. He likes playing in the rain. We have a red old umbrella at home. My brother loves it very much and often plays in the yard. He is -----------for me everyday.

\section{Put the text in the correct order and rewrite:}

- Yes, it is true. It is cloudy today and raining. It is cold outside, according to weather forecast now it's 15 degrees Celsius. It is going to be pouring rain and strong wind in the evening. I do not like rainy days.

- Hello, how are you?

My brother loves this umbrella very much and often plays in the yard. He is waiting for me everyday.

- Now I am going to the university, today I have many lectures. Are not you attending lectures? My friends and I were happy. My dog Jackie was happy too. I miss my village so much and want to go home.

- Yes, I am but I am a little bit of upset, because today is very bad weather.

- I also miss my family. My little brother is already 5 years old. He likes playing in the rain. We have a red old umbrella at home.

- Really? I love rain and walking in the rain with my favourite umbrella. I remember last year I was in village, it was pouring rain outside and then a rainbow came out. It was beautiful. I love green grass and rain drops.

- I am fine, how are you? How are you doing? Where are you going? 


\section{Create text:}

Imagine that you are in France for one month to learn French. Write e-letter to you friend, tell him/her about the weather in your city.

\section{Create text:}

Create a sample text (150-200 words) using the following verbs: (I) want, (I) love, (I) like, (I) have (someone/something), (I) need, (I) miss...

\section{Create text:}

Create a text about your favourite weather. Give arguments, cases, use familiar words/phrases...

\section{Create text:}

Make a questionnaire about weather issues. For instance, Does you mood depend on weather? What kind of weather do you like? etc. Ask your friends to fill the questionnaire and then write a sample text using statistic data.

\section{Create text:}

\section{Example:}

\section{Toastmaster}

According to an old Georgian tradition a Toastmaster is a main member, central figure and a leader of Georgian Table (Feasts). A host or the members of the feast choose a toastmaster who is an old respectful man who knows the rules of the feast well. There can be many reasons of a feast in a family: wedding or various celebrations. Therefore, the main responsibilities of a toastmaster are to say toasts and coordinate the feast as required. According to ethnographic materials, in
Make a weather forecast together, use internet resources and activate your vocabulary.

\section{Exercise type:}

Working on text.

\section{Description of exercise:}

It is possible to do the exercise at mid level of language competence. If learner is a beginner a teacher can adapt and simplify text according to the learner's knowledge and vocabulary.

The text is about Georgian traditional and cultural phenomenon - Toastmaster. Therefore, working on the text is very important in terms of raising learner's cultural competence.

\section{Strategies:}

Various strategies can be used when working on a theme: group work, role games, create different texts, make questionnaire, independent and collaborative writing. 
past period a child was taught and was getting used to become a toastmaster. A toastmaster should be well educated, talkative, patient, diplomat. People should respect him. The toastmaster's speech should only last for 3-4 minutes. He should keep the sequence of the toasts: First toast Thanks God! Then he should tell a toast to family members. Also, it is important to say a toast with regard to those who died, to peace, to homeland, to attendees. In terms of the relationships Georgian table (feast) is the best and a toastmaster should support (provide) that.

First phase: Working on the text

\section{Vocabulary:}

Responsibility/duty, old, talkative, was getting used to...

\section{Phraseology:}

Support/provide, to lay the table, to say a toast, attendees, to keep the sequence...

Second phase: text related questions:

- What is main function of the toastmaster?

- What are the characters that the toastmaster should have?

- According to the text, is it appropriate to tell long toasts at Georgian feast?

- How long should a toast last?

- What is the right sequence of the toasts?

- What type of a person was chosen as a toastmaster?
Third phase: general questions:

- Have you ever been on Georgian feast?

- Do you like the tradition of Georgian table/feast? Why?

- Which toast would you say?

- Which toast do you like and why?

- In your opinion, what is the essence/purpose of the tradition of Georgian feast and toastmaster's institute?

Fourth phase: Make a dialogue

After comprehending and discussing the text, learners are ready to make their own texts on the given topic. Make a dialogue is a very good option.

Fifth phase: role games

Doing this task requires group work. Learners in groups create imaginary social environment according to the information in text. They think about some cases, texts, 
share roles and then make presentation on the results.

Sixth phase: homework

After the various activities it is important to enhance the knowledge. For this purpose students should create texts on their favourite national tradition. The text should cover the following information: description of the tradition/traditions, own attitude, personal history or an adventure relating to a tradition, and others' (friends, family members) attitudes based on a survey/questionnaire. At that time an author should take into account the principle of logical order of the text and should get rid of lexical tautology. For the next meeting a student should present her/his work. During presentation it is possible to use visual and audio materials, role games. We could advise students to use the language clichés such as $I$ think, I like, I respect, in my opinion, as they say, according to the oldest tradition etc. (Shabatshvili. 2012, 61-65).

\section{Exercise type:}

Describe a picture:

\section{Exercise description:}

The following activity is about to describe and analyze the visual material photo. Learners ask and answer the analytical questions, make assumptions. This kind of exercise activates the cognitive and metacognitive processes, which is known as one of the effective ways of learning language. It is possible to use this type of exercise at low and mid level of language competence.

\section{Picture 1}

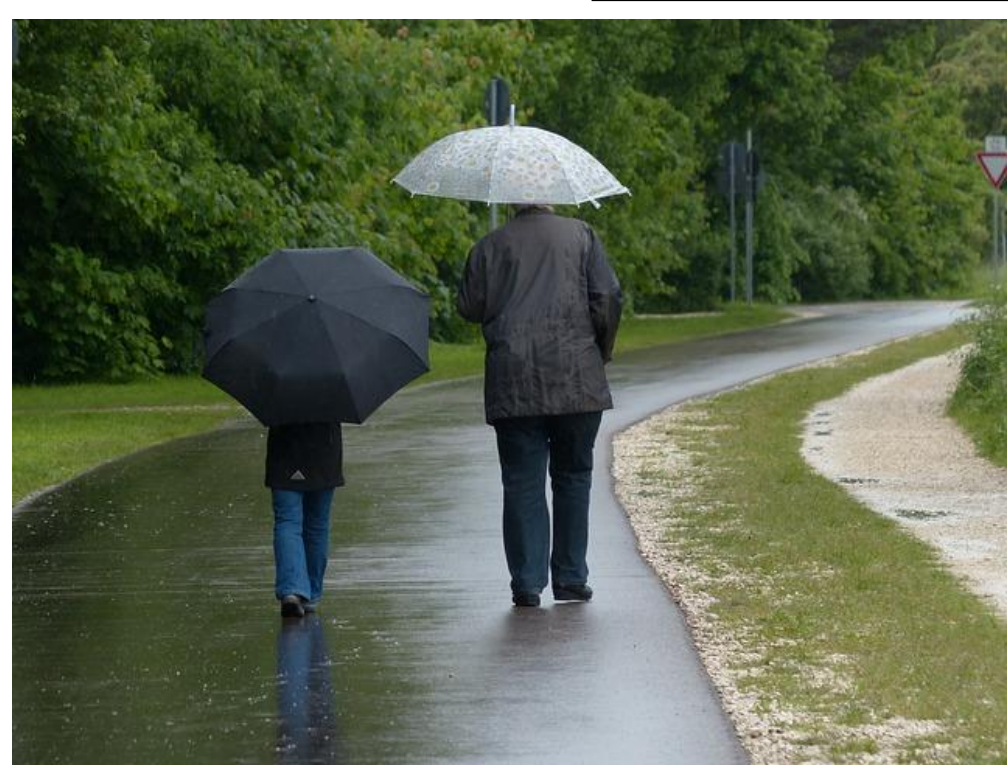




\section{Strategies:}

According to teacher's instruction, learners should use the strategies of collaborative writing, create text together, use different forms of individual and group work.

\section{Example:}

Describe a picture:

Picture 2

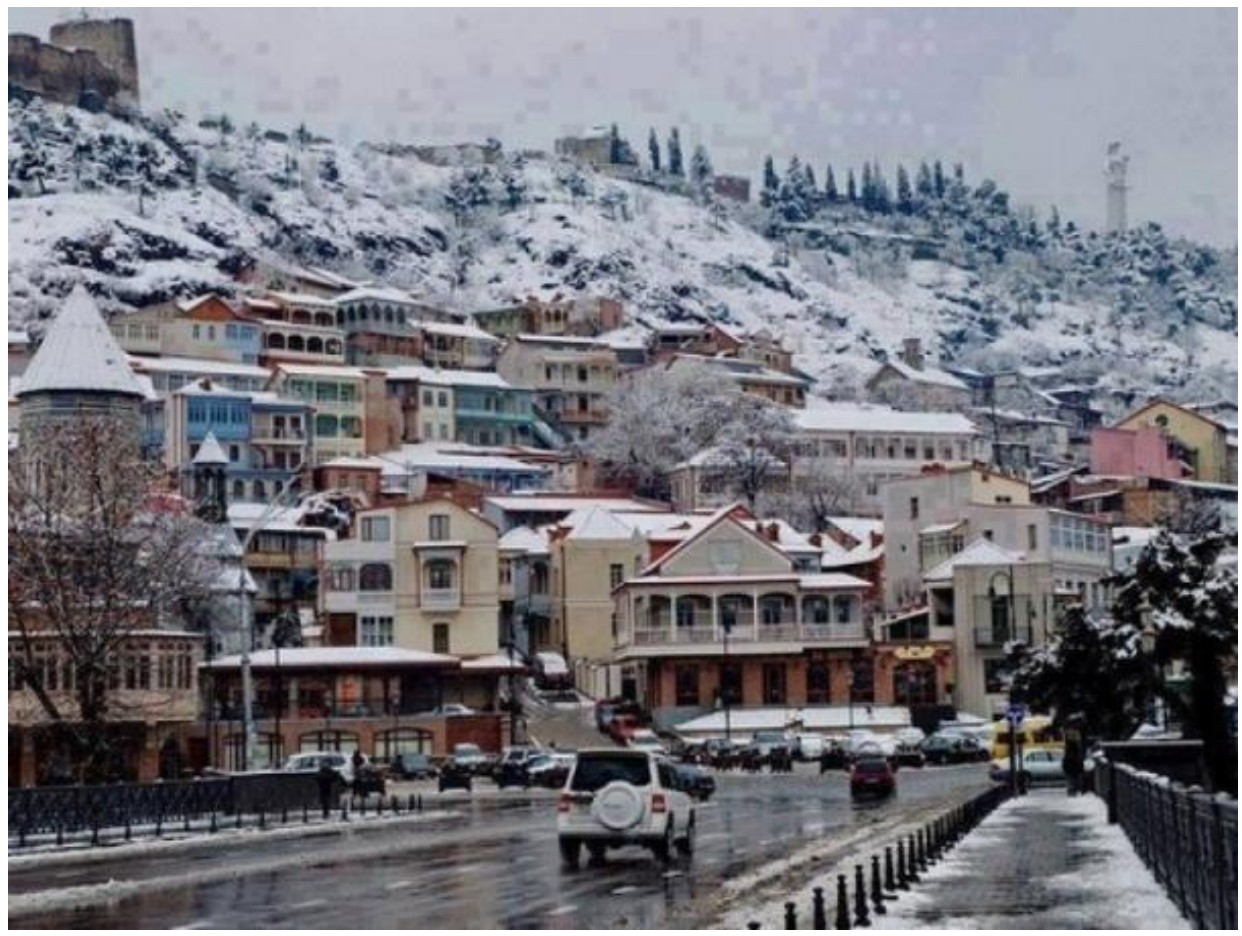

\section{First phase:}

Ask each other analytical questions:

- Who is in the photo?

- Which time of the year is?

- Where are they walking?

- What do you think what mood are they in?

- Where are grandfather and his grandson/granddaughter going?

- In your opinion what are they talking about?

\section{Second phase:}

Ask additional questions to a student sitting next to you to answer them. Then check the answers and write your comments.

\section{Third phase:}

Write the description of the picture. Use the following phrases: I think, in my opinion, as we see here etc. 


\section{Fourth phase:}

Group work: Write a sample story together according to the picture. Use illustration materials.

次

\section{Exercise type:}

Describe a picture.

\section{Exercise description:}

As previous exercise the aim of this activity is also to describe the photo. But in this case sociocultural competence is activated more, because old Tbilisi is pictured. A teacher can talk about historical facts and tradition.

Strategies: According to the teacher's instruction learners should use collaborative writing strategies, create text together, use different forms of individual and group work.

\section{Example:}

Look at the picture, to describe it write down 5 nouns, 5 adjectives and 5 verbs. Read your partner's list, specify common and different forms. Think about why you chose them and then create a sample text (150-200 words) together with your partner. In the end read the text loudly in front of the audience.

\section{Exercise type:}

Quick/free writing

\section{Exercise description:}

At supportive phase of writing quick or free writing strategies can be used. The main principle of this is: think, connect, share (Nancy Herzfeld-Pipkin). We should give the beginner authors some time to think, to discuss with partner and then each of them should be creating text during 5 minutes without break. In this case we do not pay attention to grammar mistakes, tautologies.
The results are discussed among students. In the end they present their works in front of the audience.

\section{Strategies:}

For doing this kind of writing activities a learner uses the strategies of information comprehension, organization, cognitive review and metacognitive monitoring. This helps her/him to advance writing skills and 
move to a higher level. The students observe the process of writing through their and partner's works. They understand the weaknesses and strengths, which they would consider for the next phase of the writing.

\section{2.}

\section{Exercise type:}

Fill in the questionnaire

\section{Exercise description:}

For the organization of successful writing process one of important things is to generate ideas and illustrate them coherently. In the exercise which is given as chart, student should answer the questions, give examples, use key words and phrases. By doing so a beginner author gets used to illustrate knowledge reasonably. Obviously the theme should be relevant to their level of language competence and interests in general. In addition, it is desirable that raising sociocultural competence would be the focus of the topic.

\section{Conclusion:}

In the end, once again I would like to mention that developing writing competence and teaching writing is one of the complex tasks for learner and for teacher. As we see writing activities can be various and can set various goals as well. On the other hand, there are several different approaches in teaching writing. Process oriented and collaborative writing approaches were emphasized here. Besides, it is important to consider a learner's level of language competence and therefore the phases/stages of teaching language supportive and independent writing. Also, we should take into account the upcoming results and focus on raising grammar, discursive and sociocultural competences. We could make a conclusion that only the integration of these four important factors is a key for successful writing process. So a teacher should fully understand each of its function. A teacher should plan the teaching process in advance to know well which activity and factor are relevant to each other and what will be the results that a language learner will get. 


\section{References:}

Ken Hyland, Second Language Writing, 2003, City University of Hong Kong, Cambridge University Press

Lantolp, J. P, Sociocultural theory and Second Language Learning, edited by Lantolp, Oxford University Press, 2004

Ling Xu, Lev S. Vygotsky's Sociocultural Theory and Chinese Language Teaching, 2009, NUCB JLCC, 11 (1), www.nucba.ac.jp/themes/s cic

Matsuda P.K., Process and post-process: A discursive history. Journal of Second Language Writing, 12, 2003

Mulligan C.; Garofalo R., A Collaborative Writing Approach: Methodology and student assessment; language teacher, June 5, 2011, www. Jalt-publications.orf/files/pdfarticle/art1_13.pdf, seen 5/13/2015

Nancy Herzfeld-Pipkin, with Janet Gokay, Destinations 1, Writing and Grammar for Academic Success, Instructor's Manual, Heinle, Cengage Learning, 2011.

Neomy Storch, Collaborative Writing in L2 Classrooms; publisher: Multilingual Matters, Bristol, Buffalo, Toronto, 2013

Shabashvili Giuli, Second Language: problems, approaches, strategies; publisher: Grapema, Tbilisi, 2012

Viberg, Second Language Writing Research, edited by Paul Kei Matsuda and Tony Silva, Lawrence Erlbaum Associates, New Jersey, 2005 